\title{
Keberkesanan Perkhidmatan PSP dalam Kaedah CCC bagi Pensijilan Bangunan di Negeri-Negeri Maju di Malaysia
}

\author{
Rohayati Zakaria ${ }^{1}$, Adi Irfan Che Ani ${ }^{1}$ dan Azlan Shah Ali ${ }^{2}$ \\ ${ }^{1}$ Jabatan Senibina, Fakulti Kejuruteraan Dan Alam Bina, Universiti Kebangsaan, Bangi, Selangor \\ ${ }^{2}$ Jabatan Ukur Bangunan, Fakulti Alam Bina, Universiti Malaya, Kuala Lumpur
}

\begin{abstract}
Abstrak
Sebelum tahun 2007, bangunan yang telah siap dibina hanya boleh dimasuki atau diduduki apabila Sijil Kelayakan Menduduki atau Certificate of Fitness (CF) dikeluarkan oleh Pihak Berkuasa Tempatan (PBT) kepada pemaju atau pemilik. Kebiasaannya pemaju mengalami kesukaran untuk mendapatkan CF kerana pelbagai sebab dan alasan. Bagi mengatasi masalah ini, kerajaan telah memperkenalkan satu kaedah baru iaitu Certificate of Completion And Compliance (CCC) merupakan Sijil Perakuan yang dikeluarkan oleh para Profesional yang dilantik. Di bawah kaedah CCC ini, para Profesional yang dimaksudkan adalah "Orang Utama yang Mengemukakan Permohonan" atau dikenali sebagai Principle Submitting Person (PSP). Oleh itu, kertas ini membincangkan pembolehubah-pembolehubah yang mempengaruhi perkhidmatan PSP dari aspek keselamatan dan keselesaan bangunan yang dibina kerana PSP adalah pihak yang dipertanggungjawabkan untuk mengawalselia sesuatu projek pembangunan di peringkat sebelum, semasa dan selepas projek tersebut siap. Data kuantitatif diperolehi daripada 337 responden yang terdiri daripada Arkitek-Arkitek di Negeri Selangor dan Melaka. Hasil analisis data menunjukkan enam pembolehubah yang perlu diberi perhatian serius bagi PSP melaksanakan tugasnya dengan baik dan berkualiti. Pembolehubah-pembolehubah tersebut adalah kredibiliti PSP, pengetahuan dan kepakaran PSP, akauntibiliti PSP, konflik kepentingan, sistem maklumat dan birokrasi.
\end{abstract}

Kata Kunci: Projek Pembangunan, Pensijilan Bangunan, Kaedah CCC, Perkhidmatan PSP

\subsection{Pengenalan}

Pelaksanaan sistem pengeluaran sijil Perakuan Siap Dan Pematuhan atau lebih dikenali sebagai Certificate Completion And Compliance (selepas ini disebut CCC), merupakan satu sistem baru yang diperkenalkan oleh kerajaan bagi mengatasi masalah kelewatan pihak berkuasa tempatan dalam meluluskan pelan bangunan (Fuad, 2007). Kerajaan telah memperkenalkan sistem baru ini di mana pengeluaran CCC dikeluarkan oleh para Profesional sebagai menggantikan pengeluarkan Sijil Kelayakan Menduduki atau lebih dikenali sebagai Certificate of Fitness (selepas ini disebut CF), yang dahulunya dikeluarkan oleh Pihak Berkuasa Tempatan (selepas ini disebut PBT) (Fuad, 2007). Tujuan kajian ini dilakukan ialah bagi menguji hubungan yang wujud di antara pembolehubah-pembolehubah keberkesanan perkhidmatan "Orang Utama yang Mengemukakan Permohonan" atau Principle Submitting Person (PSP) di bawah kaedah CCC. 


\subsection{Definisi Pensijilan Bangunan dan CCC}

\subsection{Pensijilan Bangunan}

Malcolm (2010) mendefinisikan pensijilan bangunan adalah satu dokumen yang diperakukan oleh PBT bagi mengesahkan bahawa sesuatu bangunan itu sebenarnya adalah sebuah kediaman persendirian. Di bawah Akta Jalan Parit Dan Bangunan 1974, mendefinisikan "bangunan" sebagai apa-apa rumah, pondok, bangsal atau kepungan beratap, samada digunakan bagi kediaman manusia atau selainnya dan juga apa-apa tembok, pagar, pelantar, pementasan, pintu pagar, tiang, pilar, paling, bingkai, papan dendeng, tempat lancar, limbungan, dermaga, tembok sambut, jeti, pentas mendarat atau jambatan, atau apa-apa binaan, tupang atau asas yang berkaitan dengan yang disebut di atas, manakala perakuan menduduki pula didefinisikan sebagai perakuan-perakuan yang diberi atau diluluskan di bawah Undang-Undang Kecil Bangunan Seragam 1984 (Malaysia 2007b).

\section{$2.2 \quad \mathrm{CCC}$}

CCC adalah merupakan perakuan bangunan yang dikeluarkan oleh para profesional yang telah dilantik oleh pihak pemaju sesuatu projek. Alan (2009) di bawah Environmental Planning and Assessment Act 1979 mendefinisikan CCC adalah merupakan satu pengesahan rasmi yang menyatakan bahawa semua kerja-kerja binaan yang dilaksanakan telah mengikut segala pelan dan kebenaran merancang yang telah diluluskan oleh pihak berkuasa. Pertubuhan Arkitek Malaysia (selepas ini disebut PAM) (2004) pula mendefinisikan CCC sebagai satu perakuan yang dikeluarkan oleh para profesional di bawah pendekatan self-certification setelah semua kerja-kerja binaan siap dilaksanakan dan mematuhi rekabentuk, pelan dan semua dokumen-dokumen yang telah dikemukakan dan diluluskan oleh PBT.

\subsection{Pensijilan Bangunan Di Bawah Kaedah CCC}

Di Australia, Parramatta City Council, telah menggunakan peruntukan di bawah Environmental Planning And Assessment Act 1979 dan Environmental Planning And Assessment Regulation 2000, menyatakan sesiapa yang dilantik sebagai "pihak utama yang memperakukan" di bawah kaedah CCC hendaklah membuat pemeriksaan ke atas projek yang dilaksanakan mengikut kebenaran pembangunan yang telah diluluskan (Susan, 2007). Di Malaysia, kaedah CCC ini memberikan tanggungjawab kepada PSP untuk memastikan sesuatu projek pembangunan yang dilaksanakan hendaklah mematuhi segala syarat-syarat teknikal yang telah diluluskan oleh PBT (Ahmad, 2008). 


\subsection{Pembolehubah Keberkesanan Perkhidmatan PSP Di Bawah Kaedah CCC}

Berdasarkan kepada kajian literatur yang telah dilakukan terdapat dua pembolehubah utama iaitu etika kerja dan sistem kerja yang mempengaruhi perkhidmatan PSP di bawah kaedah CCC dan masing-masing disokong pula dengan 5 dan 7 sub pembolehubah yang lain.

\subsection{Etika Kerja}

Etika adalah merupakan satu set prinsip moral di mana ianya merupakan suatu garis panduan yang diterima dan wajib dipatuhi oleh satu kumpulan profesional seperti doktor, peguam, jurutera, akauntan dan arkitek (Azmie, 2008). Melalui kajian literatur yang telah dilakukan, faktor etika kerja adalah merangkumi sub-faktor kredibiliti PSP, pengetahuan dan kepakaran PSP, konflik kepentingan, kebolehan PSP berhadapan masalah dan akauntibiliti PSP (Walter \& Michaal, 2010).

\subsubsection{Kredibiliti PSP}

Ahmad (2006) menyatakan bahawa kredibiliti PSP merupakan satu kekuatan yang membina karisma di mana kredibiliti PSP dilihat daripada gaya dan keikhlasan seseorang PSP itu. Kirk dan David (2008) menyatakan PSP yang mempunyai kredibiliti tinggi berupaya menyakinkan pelanggan atau pembeli bangunan untuk melabur di dalam sesuatu projek itu kerana ianya berlandaskan kepercayaan. Tambahnya lagi, seseorang arkitek yang mempunyai kredibiliti yang tinggi dan menjadi PSP mampu memastikan perjalanan sesuatu projek itu berjalan dengan licin dan lancar serta mampu memberikan perkhidmatan yang berkualiti.

\subsubsection{Pengetahuan dan Kepakaran PSP}

Seseorang PSP perlu mempunyai ilmu pengetahuan dan kepakaran di dalam bidang pembinaan yang dalam dan meluas bagi menjaga kualiti perkhidmatan yang diberikan oleh mereka. Sabda (2008) menyatakan dengan rangkaian ilmu, kemahiran, kepakaran sikap dan sifat yang baik seseorang PSP akan menjadi pekerja yang dedikasi, kreatif dan setia kepada tanggungjawabnya. Ianya boleh diibaratkan seperti 'harta tersembunyi' yang dimiliki oleh PSP itu sendiri. David dan Andrew (2010) menyokong kenyataan ini dengan menyatakan bahawa dengan pengetahuan dan kepakaran yang diperolehi, PSP boleh memberikan perkhidmatan yang terbaik dan pembeli bangunan mendapat manfaatnya kerana dapat memiliki bangunan yang berkualiti.

\subsubsection{Konflik Kepentingan}


Di bawah kaedah CCC ini hanya sebelah pihak sahaja yang terlibat di dalam proses mengeluarkan sijil perakuan siap dan pematuhan (CCC) iaitu pihak PSP. Daripada peringkat rekabentuk, penyeliaan kerja di tapak projek hinggalah kepada pengeluran CCC hanya pihak PSP yang bertanggungjawab melaksanakannya. Wan (2004) menyatakan percanggahan matlamat dan keinginan boleh membawa kesan yang serius kepada konflik kepentingan. Dalam sesebuah organisasi, konflik kepentingan diri muncul apabila PSP pada mana-mana tahap mempunyai kepentingan peribadi ketika menjalankan tugasnya.

\subsubsection{Kebolehan PSP Berhadapan Masalah}

Boleh dikatakan bahawa setiap projek yang dilaksanakan, PSP berkemungkinan berhadapan dengan masalah-masalah yang berbeza dalam mengawasi projek-projek tersebut. Ahmad (2006) menyatakan PSP perlu mempunyai kebolehan berhadapan dengan apa juga keadaan yang berlaku, ini bermakna PSP yang mempunyai karismatik yakin pada kebolehan mereka sendiri, tidak bergantung kepada pendapat dan nasihat pihak lain serta mampu menyelesaikan masalah yang berlaku di dalam sesuatu projek. Rahim et al. (2006) pula menyatakan PSP perlu mempunyai kebolehan seperti peka kepada persekitaran, proaktif, berdikari, kekuatan kendiri (mengambil risiko atau merancang sesuatu) dan intelektualiti.

\subsubsection{Akauntibiliti PSP}

Seseorang PSP mestilah mempunyai akauntibiliti atau tanggungjawab yang tinggi bagi memastikan perkhidmatan yang diberikan mempunyai kualiti yang tinggi dan ianya dapat memastikan semua kerja-kerja pembinaan yang dilaksanakan siap dengan sempurna dan mematuhi segala syarat dan peraturan yang telah ditetapkan. Holly dan Vessela (2009) menyatakan PSP yang mempunyai akauntibiliti dapat menggelakkan dari penggunaan bahan-bahan yang berkualiti rendah dan tidak mengikut piawaian yang ditetapkan.

\subsection{Sistem Kerja}

Sistem kerja merupakan satu perancangan yang telah ditetapkan dan dirangka atau keadaan amalan kerja yang sediada agar golongan professional menjadi cekap bagi melaksanakan sesuatu kerja atau tugas (Rahim et al., 2006). Selain daripada itu, sistem kerja di dalam sesebuah organisasi hendaklah dilihat sebagai satu usaha kerjasama yang berterusan dan seiring di antara individu dan organisasi dalam memantapkan sumber-sumber yang ada agar menjadi lebih kompeten dan mampu membawa organisasi ke satu tahap yang lebih cemerlang pada masa akan datang (Norhani et al., 2009). Oleh yang demikian melalui pembacaan serta kajian literatur, adalah didapati bahawa bagi birokrasi, organisasi dan pengurusan syarikat PSP, perundangan, dokumentasi, 
kewangan, sistem maklumat, dan proses dan prosedur CCC adalah merupakan sub-faktor di bawah faktor sistem kerja (Sabda, 2008).

\subsubsection{Birokrasi}

Kewujudan karenah birokrasi boleh menyebabkan keputusan yang dibuat oleh PSP tidak tepat dan tidak adil, dan mengakibatkan kualiti perkhidmatan yang diberikan berkurangan. Barbara et al. (2008) menyatakan karenah birokrasi yang berlaku di antara sektor swasta (syarikat PSP) adalah berbeza dengan birokrasi yang berlaku di dalam sektor kerajaan. Menurut Michael (2010) pula beliau menyatakan tahap birokrasi yang berlaku bergantung kepada amalan dan cara seseorang PSP itu menjalankan tugasnya. Birokrasi juga boleh menyebabkan kebanyakkan keputusan dan kerja-kerja yang dijalankan oleh PSP tidak mengikut prosedur dan proses yang betul serta perkhidmatan yang diberikan tidak berkualiti.

\subsubsection{Organisasi Dan Pengurusan Syarikat PSP}

Organisasi dan pengurusan syarikat PSP juga amat penting bagi memastikan perjalanan sesuatu projek berjalan lancar serta menyakinkan PBT dan pembeli bangunan selain mampu memberikan perkhidmatan yang lebih berkualiti. Jika organisasi dan pengurusan syarikat PSP kucar kacir penumpuan terhadap bidang kerja tidak diutamakan dan boleh menyebabkan hasil kerja mereka tidak berkualiti. Asma (2009) menyatakan bahawa budaya organisasi pengurusan PSP di Jepun adalah berdasarkan orientasi kolektivistik, iaitu pekerjanya saling bergantung dan membantu di antara satu sama lain. Jika PSP tidak dibantu dan disokong oleh kakitangan syarikat maka banyak kerja-kerja PSP tertangguh dan hasilnya sudah pasti tidak berkualiti

\subsubsection{Perundangan}

Setiap projek pembangunan yang hendak diselia oleh PSP hendaklah mematuhi dan merujuk kepada undang-undang yang telah ditetapkan tanpa ada kompromi untuk menggelakkannya. Perundangan yang digunapakai pada dasarnya telah ditetapkan di dalam sesuatu akta dan ianya tidak boleh dipinda sewenang-wenangnya oleh mana-mana pihak sebelum mendapat kebenaran untuk berbuat demikian. Azlan-Shah et al. (2010) menyatakan bahawa tertakluk di bawah undang-undang kecil PBT segala perubahan yang berlaku di dalam sesuatu projek pembangunan PSP perlu merujuk kepada keperluan yang telah ditetapkan di dalamnya. Oleh yang demikian bagi menjaga kepentingan syarikat dan kepentingan pembeli bangunan serta bagi melancarkan kerja-kerja sesuatu pembinaan, PSP perlu tahu dan mahir dengan tafsiran perundangan dan akta-akta yang terlibat.

\subsubsection{Dokumentasi}


Dokumen-dokumen yang perlu dikemukakan oleh PSP sepanjang proses pembinaan adalah penting bagi memastikan projek yang dilaksanakan berjalan lancar. Dokumentasi tidak lengkap, boleh menyebabkan pelbagai perkara tidak dapat dirujuk dengan betul dan PSP terpaksa membuat rujukan kepada pihak lain dan sebagainya. Keadaan ini mengurangkan dan melemahkan kualiti perkhidmatan yang diberikan oleh PSP. Keoki et al. (2008) menyatakan bahawa PSP perlu merujuk kepada dokumen-dokumen yang lengkap dan sempurna agar tidak berlakunya perkara-perkara yang tidak diingini seperti penggunaan yang salah, ketidakpatuhan syarat dan sebagainya.

\subsubsection{Kewangan}

Di dalam melaksanakan sesuatu projek pembinaan, sumber kewangan memainkan peranan yang amat penting bagi memastikan proses pembinaan berjalan lancar. Sumber kewangan yang mencukupi adalah diperlukan disepanjang proses pembinaan bagi memastikan projek pembinaan itu berjalan lancar tanpa sebarang masalah (Simon, 2009). George (2008) menyatakan bahawa tanggungjawab menjaga kewangan dan sumber berada di dalam had yang ditentukan merupakan satu daripada peranan utama PSP. Sekiranya sumber kewangan tidak mencukupi bagi melaksanakan projek pembinaan maka PSP tidak akan dapat melaksanakan tanggungjawab yang diberikan dengan baik dan berkualiti. Kemungkinan ini menyebabkan CCC tidak dapat dikeluarkan oleh PSP dalam tempoh yang sepatutnya.

\subsubsection{Sistem maklumat}

Industri pembangunan adalah satu industri yang komplek dan rumit. Ia memerlukan satu sistem yang efisyen bagi memastikan semua maklumat dan data dapat disimpan dan direkodkan dengan baik sebagai rujukan PSP (Nigel \& Ellen, 2007). Dengan adanya satu sistem maklumat yang terkini dan bersesuaian maka segala maklumat dan data sesuatu projek dapat diuruskan dengan mudah dan cepat oleh PSP. Dengan kemudahan ini PSP dapat memberi tumpuan kepada perkhidmatan yang berkualiti kepada pelanggan.

\subsubsection{Proses dan Prosedur CCC}

Proses dan prosedur CCC yang telah ditetapkan adalah banyak dan rumit terutamanya bagi Proses Perakuan Berperingkat. PSP perlu mematuhi dan melengkapkan setiap borang yang terlibat di sepanjang proses pembinaan berjalan. Mana-mana proses yang tidak mengikut prosedur yang ditetapkan menyebabkan kerja berulang kali terpaksa dilakukan oleh PSP. Stuart (2008) menyatakan bagi mematuhi semua proses dan prosedur CCC ini PSP perlu mendapat kerjasama daripada pihak-pihak lain yang 
terlibat seperti kontraktor utama, sub-kontraktor, PBT dan sebagainya. Kerjasama yang wujud di antara pihak-pihak yang terlibat dapat menjamin kualiti perkhidmatan yang diberikan.

\subsection{Kaedah Kajian}

Penyelidikan ini hanya merangkumi bangunan-bangunan yang menggunapakai sistem CCC sahaja, iaitu permohonan yang dikemukakan kepada PBT selepas 12 April 2007.Pemilihan kawasan penyelidikan pula merangkumi negeri-negari maju di Malaysia iaitu Negeri Selangor dan Negeri Melaka sahaja di mana kedua-duanya telah diiktiraf sebagai negeri maju di Malaysia (UPEN 2005; UPEN 2010). Bagi pemilihan kategori bangunan ianya merangkumi semua kategori bangunan memandangkan proses dan prosedur pengeluaran $\mathrm{CCC}$ adalah sama bagi semua katogeri bangunan. Bagi pemilihan responden pula ianya terdiri dari pihak yang mengeluarkan CCC ini, iaitu Arkitek Profesional dan Pelukis Pelan yang berdaftar dengan Lembaga Arkitek Malaysia (selepas ini disebut LAM) (Fuad, 2007). Rangka kerja teori bagi penyelidikan ini adalah seperti yang ditunjukkan di dalam Rajah 1.

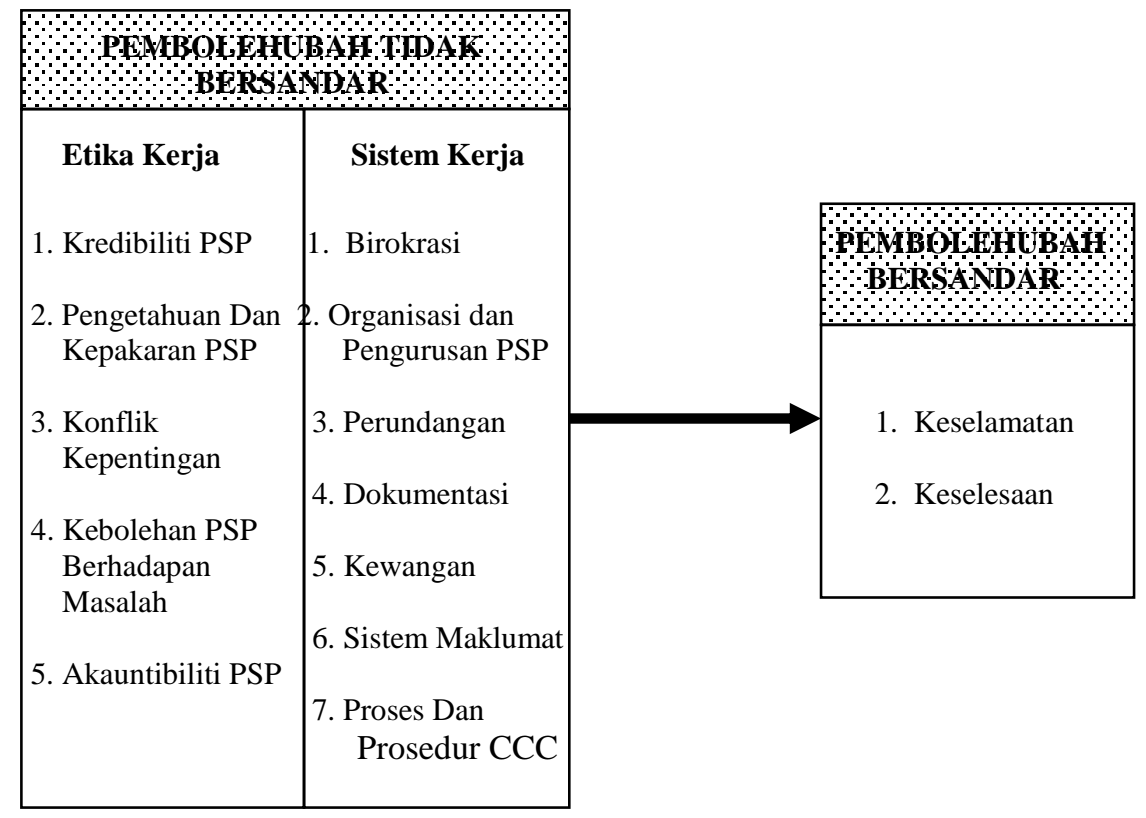

Rajah 1 : Rangka kerja teori peyelidikan

Strategi penyelidikan yang digunakan di dalam penyelidikan ini adalah berbentuk kaedah kuantitatif. Kaedah kuantitatif ini adalah merupakan sesuatu yang boleh diukur dengan menggunakan nombor dan dianalisis menggunakan prosedur statistik di mana ianya 
menghasilkan data yang tidak abstrak, mempunyai kebolehpercayaan dan tidak diragui (Naoum, 2012). Menurut Sekaran dan Bougie (2010), bagi populasi responden yang ramai penggunaan kaedah persampelan adalah paling sesuai. Penyelidik menggunakan kaedah persampelan dan perlu mendapatkan seramai 322 orang responden (minima-merujuk kepada jadual) daripada jumlah sebenar sebanyak 1997. Oleh kerana kajian ini melibatkan jumlah responden yang besar maka bagi menimakan kos, penyelidik menggunakan kaedah pos kerana ianya mudah dan sesuai (Sarantakos, 1988). Penyelidik telah menerima semula borang soal selidik yang telah diedarkan sebanyak 337 borang (yang boleh digunakan) dan melepasi jumlah minima yang diperlukan. Semua data-data ini dianalisis dengan menggunakan SPSS versi 19.

\subsection{Analisis Data dan Perbincangan}

\subsection{Prestasi Bangunan}

Jadual 1 menunjukkan keputusan soal selidik yang dilakukan. Lebih separuh (melebihi 50\%) responden menjawab tidak pernah menerima sebarang aduan berkenaan kemalangan yang berlaku disebabkan oleh kualiti bangunan dan aduan berkenaan ketidakselesaan menduduki sesebuah bangunan itu disebabkan oleh rekabentuk bangunan tersebut. Responden-responden yang terlibat menjawab soalan ini berdasarkan kepada aduan yang telah diterima daripada pemilik atau penghuni bangunan yang menduduki bangunan tersebut.

Jadual 1 : Aduan

\begin{tabular}{|l|c|c|}
\hline \multirow{2}{*}{ Jumlah Aduan } & \multicolumn{2}{|c|}{ Peratusan $(\mathbf{n}=\mathbf{3 5 3})$} \\
\cline { 2 - 3 } & Kemalangan & Ketidakselesaan \\
\hline Tiada Aduan & 68.6 & 56.5 \\
Kurang 10 Aduan & 24.8 & 36.4 \\
10 - 20 Aduan & 4.8 & 4.3 \\
21 - 30 Aduan & 1.0 & 1.4 \\
31 -40 Aduan & 0.5 & 0.5 \\
41- 50 Aduan & 0.3 & 0.5 \\
Lebih 50 Aduan & 0 & 0.4 \\
\hline Jumlah & $\mathbf{1 0 0 . 0}$ & $\mathbf{1 0 0 . 0}$ \\
\hline
\end{tabular}

Keputusan ini membayangkan bahawa di sepanjang tempoh kaedah CCC ini dilaksanakan, PSP yang dilantik telah menjalankan tanggungajwabnya dengan penuh profesional serta dapat mematuhi segala syarat, proses dan prosedur yang telah ditetapkan. Dengan menjaga kualiti perkhidmatannya disepanjang tempoh sesuatu pembangunan itu dilaksanakan ianya menjamin keselamatan dan keselesaan bangunan yang dibina. Sekiranya kualiti dan rekabentuk bangunan yang dibina memenuhi kehendak pelanggan seperti yang telah diluluskan maka tidak ada masalah dan aduan berkenaan kualiti dan rekabentuk bangunan tersebut. Semakin kurang bilangan aduan yang diterima menunjukkan bangunan yang dibina itu adalah bangunan yang berkualiti (Azlan 
Shah et al., 2010); dan secara tidak langsung ianya membuktikan bahawa PSP telah menjalankan tanggungjawabnya dengan baik dan perkhidmatan yang diberikan adalah perkhidmatan yang berkualiti.

\subsection{Menilai Kesahihan Pembolehubah}

Bagi menilai sejauh mana pembolehubah-pembolehubah di dalam penyelidikan ini boleh dipercayai, penyelidik telah menggunakan nilai pekali Cronbach's Alpha bagi mengira setiap pembolehubah yang terlibat. Ini bertujuan melihat samada pembolehubah yang digunakan adalah pembolehubah yang konsisten dan mempunyai kebolehpercayaan yang tinggi (Pallant, 2001). Jadual 2 menunjukkan hasil keputusan ujian bagi pekali Cronbach's Alpha tersebut.

Jadual 2: Keputusan Ujian Kebolehpercayaan

\begin{tabular}{|c|l|c|c|}
\hline \multirow{2}{*}{ Bil. } & \multicolumn{1}{|c|}{ Pembolehubah } & \multicolumn{2}{c|}{$\begin{array}{c}\text { Nilai pekali } \\
\text { Cronbach's Alpha }\end{array}$} \\
\cline { 3 - 4 } & & \multicolumn{1}{c|}{ Keselamatan } & .865 \\
\hline 1 & Kredibiliti PSP & .866 & .867 \\
\hline 2 & Pengetahuan Dan Kepakaran PSP & .868 & .868 \\
\hline 3 & Konflik Kepentingan & .870 & .865 \\
\hline 4 & Kebolehan PSP Berhadapan Masalah & .866 & .866 \\
\hline 5 & Akauntibiliti PSP & .868 & .867 \\
\hline 6 & Birokrasi & .870 & .866 \\
\hline 7 & Organisasi Dan Pengurusan Syarikat PSP & .868 & .865 \\
\hline 8 & Perundangan & .867 & .865 \\
\hline 9 & Dokumentasi & .868 & .869 \\
\hline 10 & Kewangan & .870 & .866 \\
\hline 11 & Sistem Maklumat & .868 & .867 \\
\hline
\end{tabular}

Keputusan Jadual 2 ini dengan jelas membuktikan bahawa semua pembolehubah yang terlibat di dalam penyelidikan ini mempunyai kebolehpercayaan yang tinggi serta konsisten di mana nilai pekalinya melebihi 0.70. Menurut Pallant (2001) pembolehubah yang sesuai dan boleh diterima pakai mempunyai nilai pekali melebihi 0.70 .

\subsection{Bentuk Taburan Pembolehubah Perkhidmatan PSP}

Penyelidikan ini menggunakan kaedah parametrik kerana data-data yang diperolehi tertabur secara normal. Secara ukuran kepencongan bagi menentukan bentuk kenormalan sesuatu pembolehubah itu adalah di antara -3 dan 3 ( Lind et al., 2003 ) di mana nilai-p yang tidak signifikan melebihi 0.05 (Sheridan \& Lyndall, 2002). Jadual 3 menunjukkan secara terperinci keputusan ujian kepencongan dan kenormalan yang dilakukan. 
Jadual 3: Ukuran Kepencongan dan Ujian Kenormalan Pembolehubah

\begin{tabular}{|c|c|c|c|c|c|c|}
\hline \multirow{3}{*}{ Bil } & \multirow{3}{*}{ Pembolehubah } & \multicolumn{2}{|c|}{$\begin{array}{c}\text { Ukuran } \\
\text { Kepencongan }\end{array}$} & \multicolumn{2}{|c|}{$\begin{array}{c}\text { Ujian } \\
\text { Kenormalan }\end{array}$} & \multirow{3}{*}{$\begin{array}{c}\text { Kesimpulan } \\
\text { Taburan }\end{array}$} \\
\hline & & \multicolumn{2}{|c|}{ Statistik } & \multicolumn{2}{|c|}{ Nilai-p } & \\
\hline & & Keselamatan & Keselesaan & Keselamatan & Keselesaan & \\
\hline 1 & Kredibiliti PSP & -1.261 & -0.947 & 0.065 & 0.070 & Normal \\
\hline 2 & $\begin{array}{l}\text { Pengetahuan Dan } \\
\text { Kepakaran PSP }\end{array}$ & -1.353 & -1.058 & 0.078 & 0.073 & Normal \\
\hline 3 & Konflik Kepentingan & -0.371 & -0.275 & 0.057 & 0.061 & Normal \\
\hline 4 & $\begin{array}{l}\text { Kebolehan PSP } \\
\text { Berhadapan Masalah }\end{array}$ & -1.214 & -0.981 & 0.066 & 0.069 & Normal \\
\hline 5 & Akauntibiliti PSP & -1.466 & -1.154 & 0.082 & 0.087 & Normal \\
\hline 6 & Birokrasi & -0.458 & -0.271 & 0.086 & 0.091 & Normal \\
\hline 7 & $\begin{array}{l}\text { Organisasi Dan } \\
\text { Pengurusan Syarikat PSP }\end{array}$ & -0.588 & -0.466 & 0.059 & 0.064 & Normal \\
\hline 8 & Perundangan & -0.663 & -0.594 & 0.084 & 0.079 & Normal \\
\hline 9 & Dokumentasi & -1.036 & -0.862 & 0.093 & 0.086 & Normal \\
\hline 10 & Kewangan & -0.247 & -0.241 & 0.077 & 0.075 & Normal \\
\hline 11 & Sistem Maklumat & -0.667 & -0.669 & 0.056 & 0.063 & Normal \\
\hline 12 & $\begin{array}{l}\text { Proses Dan Prosedur } \\
\text { CCC }\end{array}$ & -0.999 & -0.715 & 0.097 & 0.092 & Normal \\
\hline
\end{tabular}

\subsection{Hubungan Di Antara Pembolehubah Keberkesanan Perkhidmatan PSP}

Bagi tujuan ini, penyelidik menggunakan pekali korelasi Pearson untuk menguji dan mengukur kekuatan hubungan yang mungkin wujud di antara pembolehubah-pembolehubah memandangkan kesemua pembolehubah tersebut tertabur secara normal. Menurut Zulkarnain dan Hishamuddin (2001) bagi menggelakkan nonsense correlation (dua dimensi yang tiada kaitan memberikan nilai pekali korelasi yang tinggi), sub-faktor tidak diukur hubungannya dengan faktor utama kerana ianya merupakan satu kumpulan data yang sama. Jadual 4 dapat dilihat secara terperinci hubungan yang wujud di antara pembolehubah-pembolehubah yang terlibat di dalam kajian ini. 
Jadual 4: Hubungan Yang Wujud di antara Pembolehubah-Pembolehubah

\begin{tabular}{|c|c|c|c|c|c|}
\hline \multirow{2}{*}{ Bil } & Bersandar & \multicolumn{2}{|c|}{ Keselamatan } & \multicolumn{2}{|c|}{ Keselesaan } \\
\hline & & $\begin{array}{l}\text { Korelasi } \\
\text { Pearson }\end{array}$ & Hubungan & $\begin{array}{l}\text { Korelasi } \\
\text { Pearson }\end{array}$ & Hubungan \\
\hline 1 & Kredibiliti PSP & $-.227 * *$ & Linear tinggi & $-.234 * *$ & Linear tinggi \\
\hline 2 & Pengetahuan Dan Kepakaran PSP & $-.193 * *$ & Linear tinggi & $-.195 * *$ & Linear tinggi \\
\hline 3 & Konflik Kepentingan & $-.136^{*}$ & Linear sederhana & .044 & Tidak signifikan \\
\hline 4 & $\begin{array}{l}\text { Kebolehan PSP Berhadapan } \\
\text { Masalah }\end{array}$ & .006 & Tidak signifikan & -.023 & Tidak signifikan \\
\hline 5 & Akauntibiliti PSP & $-.241 * *$ & Linear tinggi & -.076 & Tidak signifikan \\
\hline 6 & Birokrasi & .021 & Tidak signifikan & $-.159 *$ & Linear sederhana \\
\hline 7 & $\begin{array}{l}\text { Organisasi Dan Pengurusan } \\
\text { Syarikat PSP }\end{array}$ & -.080 & Tidak signifikan & -.006 & Tidak signifikan \\
\hline 8 & Perundangan & -.047 & Tidak signifikan & -.009 & Tidak signifikan \\
\hline 9 & Dokumentasi & -.049 & Tidak signifikan & -.054 & Tidak signifikan \\
\hline 10 & Kewangan & .019 & Tidak signifikan & .007 & Tidak signifikan \\
\hline 11 & Sistem Maklumat & $-.160 *$ & Linear sederhana & -.110 & Tidak signifikan \\
\hline 12 & Proses Dan Prosedur CCC & -.021 & Tidak signifikan & -.011 & Tidak signifikan \\
\hline
\end{tabular}

Nota : * Signifikan pada aras 5 peratus

** Signifikan pada aras 1 peratus

Semua bacaan negatif yang ditunjukkan menandakan terdapatnya hubungan linear signifikan samada tinggi, sederhana ataupun sangat rendah di antara pembolehubah tidak bersandar dengan pembolehubah bersandar yang diuji. Melalui Jadual 4 dapat dilihat bahawa terdapat hubungan linear signifikan yang tinggi (pada aras 1 peratus) di antara pembolehubah kredibiliti PSP, pengetahuan dan kepakaran PSP serta akauntibiliti PSP dengan aspek keselamatan.

Dapat juga dilihat bahawa terdapat hubungan linear signifikan yang tinggi (pada aras 1 peratus) di antara pembolehubah kredibiliti PSP serta pengetahuan dan kepakaran PSP dengan aspek keselesaan. Manakala terdapat hubungan linear yang signifikan sederhana (pada aras 5 peratus) bagi pembolehubah konflik kepentingan, dan sistem maklumat dengan aspek keselamatan. Selain daripada itu terdapat juga hubungan linear yang signifikan sederhana bagi pembolehubah birokrasi dengan aspek keselesaan.

Bagi memberikan perkhidmatan yang terbaik dan berkualiti maka PSP hendaklah menitik beratkan pembolehubah-pembolehubah yang memberi kesan ke atas perkhidmtannya. Berdasarkan kepada hasil kajian ini, pembolehubah yang perlu diberikan perhatian yang serius adalah kredibiliti PSP, pengetahuan dan kepakaran PSP, akauntibiliti PSP, konflik kepentingan, sistem maklumat dan 
birokrasi. Pembolehubah-pembolehubah signifikan yang telah dikenalpasti juga boleh menjadi satu panduan kepada PSP dalam memelihara kualiti perkhidmatan yang diberikan agar kaedah CCC ini mencapai matlamatnya. Ringkasan daripada analisis data yang diperolehi adalah seprti berikut:-

i) Keberkesanan perkhidmatan PSP di bawah kaedah CCC di negeri-negeri maju di Malaysia berada ditahap yang baik berdasarkan kepada jumlah aduan kemalangan dan ketidakselesaan yang diterima.

ii) Etika kerja dan sistem kerja memainkan peranan yang penting dalam memastikan PSP dapat memelihara keprofesionalannya serta dapat memberikan perkhidmatan yang berkualiti bagi menjamin keselamatan dan keselesaan penghuni bangunan.

iii) Masalah konflik kepentingan dan birokrasi timbul berkemungkinan disebabkan PSP hanya mengikut segala kehendak pihak pelanggannya sahaja (pemaju) dan tiada campur tangan daripada pihak-pihak lain.

iv) Analisis data juga menggambarkan sekiranya PSP melaksanakan tanggungjawabnya dengan mematuhi segala etika kerja, sistem kerja, syarat, proses, prosedur dan perundangan yang ditetapkan, maka peranan PSP di bawah kaedah CCC ini adalah berkesan bagi mencapai tujuan pensijilan ke atas sesebuah bangunan dari segi keselamatan dan keselesaan bangunan.

v) Walaupun pembolehubah konflik kepentingan dan birokrasi mempunyai hubungan yang sederhana sahaja tetapi hasil maklumbalas responden menunjukkan kedua-duanya juga mempengaruhi kualiti perkhidmatan PSP.

vi) Faktor kredibiliti, pengetahuan dan kepakaran, akauntibiliti PSP perlu dijaga dan di praktikan oleh PSP dalam menjamin keberkesanan kualiti perkhidmatan yang diberikan samada kepada pemaju atau pembeli bangunan.

\subsection{Kesimpulan}

Melalui hasil penyelidikan yang telah diperolehi jelas menunjukkan bahawa terdapat penemuan-penemuan utama yang penting dan perlu diberi perhatian serius oleh pihak Kementerian Perumahan dan Kerajaan Tempatan (KPKT) dan PBT untuk menilai keberkesanan perkhidmatan yang diberikan oleh PSP di bawah kaedah CCC ini agar matlamat pelaksanaan kaedah CCC dalam usaha pihak kerajaan menambahbaik sistem sediada demi kepentingan awam dapat tercapai sepenuhnya. Walaubagaimanapun ternyata bahawa kaedah CCC ini mempunyai potensi untuk mengatasi masalah pada sistem lama iaitu CF dalam menangani masalah masa kelulusan. Ini kerana pihak yang menyelia keseluruhan projek (PSP) sendiri yang akan mengeluarkan sijil perakuan 
bangunan (CCC). Namun begitu merujuk kepada hasil analisis yang dilakukan, kajian ini mendapati enam pembolehubah yang perlu diberi perhatian seperti yang diterangkan sebelum ini.

Selain daripada enam pembolehubah yang perlu diberi perhatian, terdapat juga pembolehubah-pembolehubah yang diperolehi melalui kajian literatur secara tidak langsung mempengaruhi keberkesanan perkhidmatan PSP di bawah kaedah CCC ini. Ini membawa maksud bahawa dengan mengabaikan pembolehubah-pembolehubah ini ianya juga boleh memberi kesan kepada kualiti perkhidmatan PSP terhadap keselamatan dan keselesaan bangunan yang dibina walaupun kesannya tidaklah sebesar enam pembolehubah utama yang dinyatakan tadi.

\section{Rujukan}

Ahmad, N. J. (2006). Membina karisma. Selangor: PTS Professional Publishing.

Ahmad, S. (2008). Benefits of CCC system in term of local authorities experience. Majlis Perbandaran Kajang.

Alan, A. H. (2009). The law affecting valuation of land in Australia. Sydney: Federation Press.

Asma, A. (2009). Ke arah global dimensi budaya dalam pengurusan Malaysia. Ed. ke-3. Kuala Lumpur. Terjemahan Negara Malaysia Berhad.

Azlan-Shah, A., Kamaruzzaman, S.N., Abdul-Samad Z. \& Pitt, M.R. (2010). A study of design performance of refurbishment projects in Malaysia. Journal of Asian Architecture and Building Engineering, 9(2), 323-329.

Azmie, M. Z. (2008). Sopan daripada perspektif pengurusan organisasi. Kuala Lumpur: Utusan Publications \& Distributors Sdn. Bhd.

Barbara, A. B., Mack, C. S. \& Steffen, W. S. (2008). American government and politics today. New York: Cengage Learning Inc.

David, C. \& Andrew, W. (2010). The architect in practice. Ed. ke-10. United Kingdom: Blackwell Publishing.

Fuad, I. (2007). Pelaksanaan kaedah pengeluaran perakuan siap dan pematuhan oleh para profesional. Kertas Kerja Persidangan Mempertingkatkan Sistem Penyampaian Perkhidmatan Kerajaan-Penambahbaikan Urusan-urusan Pemajuan Serta Penyenggaraan dan pengurusan Hartanah. Anjuran Kementerian Perumahan dan Kerajaan Tempatan. Pusat Bandar Damansara, Kuala Lumpur, 14 April.

George, E. D. (2008). Rekabentuk kejuruteraan: Pendekatan bahan dan pemprosesan. Ed. ke-3. Kuala Lumpur: Institut Terjemahan Negara Malaysia.

Holly, W. C. \& Vessela, V. (2009). What you really need to know to pass the LEED AP homes exam. Belmont: Professional Publications Inc.

Keoki, S.S., Richard, H. C. \& Glenn, A. S. (2008). Construction project management: A practical guide to field construction management. Canada: John Wiley \& Sons Inc.

Kirk, H. \& David, H. W. (2008). Evidence-based design for multiple building type. New Jersey: John Wileys \& Sons Inc. 
Lind, D.A., Marchal, W.G. \& Wathen, S.A. (2003). Basic statistics for business and economics. United States: Mc Graw Hill.

Malaysia. (2007b). Undang-undang kecil bangunan seragam 1984. (P.W.5178/85).

Malcom, T. (2010). What is a certificate of occupancy?. Diperolehi pada 6 Januari, 2011 dari, http://www.wisegeek.org/what-is-acertificate-of-occupancy.htm

Michael, L. (2010). Streel-level bureaucracy: Dilemmas of the individual in public services. United State: Russell Sage Foundation.

Naoum, S. G. (2012). Dissertation research \& writing for construction students. Ed. ke-3. UK: Taylor \& Francis Inc.

Nigel, M. S. C. \& Ellen, M. M. (2007). Nanoscale: Issue and perspectives for the nano century. New Jersey: John Wiley \& Sons Inc.

Norhani, B., Yoong, S. K. \& Hanipah, H. (2009). Hubungan antara peranan individu dan organisasi dengan amalan pembangunan kerjaya. Journal of Human Capital Development, 2(1), 13-24.

Pallant, J. (2001). SPSS survival manual. USA: Open University Press.

PAM. (2004). Government's proposal to substitute the CFO with CCC issued by professional architects and engineers. Government Liaison Committee Report, Tahun 2004.

Rahim, A. R., Sufean, H. \& Jalil, O. (2006). Hala tuju pengurusan: Sumber manusia dan kerjaya. Kuala Lumpur: Utusan Publications \& Distributors Sdn. Bhd.

Sabda, S. (2008). Karenah organisasi-Mengagumi pekerja faktor utama produktiviti. Kuala Lumpur: Utusan Publications \& Distributors Sdn. Bhd.

Sarantakos, S. (1988). Social Research. New York: Palgrave.

Sekaran, U. \& Bougie, R. (2010). Research methods for business: A skill building approach. Ed. ke-5. New York: John Wiley \& Sons, Inc.

Sheridan, J. C. \& Lyndall, G. S. (2002). Analysis without anguish. Ed. ke-11. Australia: John Wiley \& Sons Ltd.

Simon, A. B. (2009). Risk and financial management in construction. England: Gower Publishing Ltd.

Stuard, S. (2008). CDM regulations 2007 procedures manual. Ed. ke-3. Oxford: Blackwell Publishing.

Susan, T. (2007). Planning Australia: An overview of urban and regional planning. New York: Cambridge University Press.

UPEN (2005). Selangor maju 2005: Konsep yang menjadi realiti. Shah Alam, Selangor: Seksyen Penswastaan dan Ekonomi.

UPEN (2010). Organization of Economic Coorporation \& Development (OECD) Akui Melaka negeri maju. Diperolehi dari, http://www.bharian.com.my/articles/OECDakuiMelakasediacapaistatusnegerimaju/Article/

Walter, R. \& Michaal, D. (2010). The professional practice of landscape architecture. Ed. ke-2. New Jersey: John Wiley \& Sons Inc.

Wan, S. W. (2004). Etika dan amalan perniagaan. Kuala Lumpur: Utusan Publications \& Distributors Sdn. Bhd.

Zulkarnain, Z. \& Hishamuddin, M. S. (2001). Analisis data: Menggunakan SPSS windows. Johor: Universiti Teknologi Malaysia. 